ONLINE MUTATION REPORT

\title{
PTPN1 1 mutations in patients with LEOPARD syndrome: a French multicentric experience
}

\author{
B Keren, A Hadchouel, S Saba, Y Sznajer, D Bonneau, B Leheup, O Boute, D Gaillard, D Lacombe, \\ V Layet, S Marlin, G Mortier, A Toutain, C Beylot, C Baumann, A Verloes, H Cavé, for the French \\ Collaborative Noonan Study Group
}

J Med Genet 2004;41:e1 17 (http://www.jmedgenet.com/cgi/content/full/41/11/e1 17). doi: 10.1136/jmg.2004.021451

EOPARD syndrome (LS) is a rare autosomal dominant disorder characterised by lentigines and café au lait spots, LEKG anomalies, ocular hypertelorism, pulmonary stenosis (PS), abnormal genitalia, retardation of growth, and deafness, and has been successively considered as a distinct syndrome and later as a clinical variant of Noonan syndrome (NS). Some months after the discovery of heterozygous mutations in the PTPNII gene in roughly $40 \%$ of clinically typical NS patients, ${ }^{1}$ Digilio et al ${ }^{2}$ reported the presence of PTPN11 mutations in nine out of 10 unrelated patients with LS or NS with multiple lentigines or café au lait spots, confirming that both disorders are allelic variants. PTPNII encodes SHP-2, a ubiquitously expressed non-receptor-type tyrosine phosphatase involved in a variety of cytokine and growth factor initiated signal transduction processes. SHP-2 contains two tandem SH2 domains encoded by exons 1 to 4 at the $\mathrm{N}$ terminus, and a phosphatase domain (PTP) encoded by exons 7 to 13 at the $C$ terminus. Three different mutations have been described so far in LS, all located in the PTP domain. $^{2-4}$ These mutations are believed to disrupt the interaction between the N-SH2 and PTP domains, leading to increased phosphatase activity as similarly observed in NS. However, mutations described in LS seems to be highly specific for this syndrome.

In an attempt to better define the pattern of PTPNII mutations responsible for LS and their correlation with clinical presentation, we here report results obtained in 14 families.

\section{METHODS}

DNA samples obtained from peripheral leucocytes of 14 unrelated propositi with a clinical diagnosis of LS were referred to our laboratory by confirmed clinician geneticists for PTPN11 mutation screening. For eight of them, parental DNA was also collected. Bi-directional direct sequencing of PTPN11 exons 2, 3, 4, 7, 8, 12, and 13, and their flanking intron-exon boundaries was performed for each patient using the Big Dye Terminator Cycle Sequencing Ready Reaction Kit (Applied Biosystems, Foster City, CA, USA). Reaction products were run on an ABI 3100 Genetic Analyzer (Applied Biosystems). After analysis using ABI PRISM DNA Analysis software (Applied Biosystems), sequences were aligned using Seqscape analysis software (Applied Biosystems) and compared with the reference sequences for genomic DNA (GenBank accession number NT_009775.14) and mRNA (GenBank accession number NM_002834.3).

Clinical data were gathered with a standard datasheet used for all NS/LS patients referred to our centre. Frequencies of clinical features for the two major mutations were compared using Fisher's exact test.

\section{Key points}

- LEOPARD syndrome (LS) is an autosomal dominant disorder characterised by lentigines and café au lait spots, EKG anomalies, ocular hypertelorism, pulmonary stenosis, abnormal genitalia, retardation of growth, and deafness. So far, three distinct mutations of the PTPN 11 gene have been reported in 15 patients with LS.

- Fourteen unrelated propositi with a clinical diagnosis of LS from the French Multicentric Noonan Study were screened for PTPN1 1 mutations.

- The two previously described recurrent mutations, Y279C in exon 7 and T468M in exon 12, were identified, respectively, in six and four unrelated patients.

- Two new mutations were identified. A substitution Y279S was found in one child who developed acute myeloid leukaemia (AML). Missense variation Q510P was found in two unrelated patients.

- Among eight parents whose parental DNA was available, three mothers and one father were carriers and clinically affected.

- No mutations were found in one atypical, familial case further exhibiting marfanoid habitus.

- Comparison of T468M and Y279C phenotypes showed a significant difference for EKG anomalies, and possible (but not statistically significant) trends for heart defect, growth retardation, and deafness.

- $\mathrm{AML}$, probably a not so rare complication of Noonan syndrome, is reported here for the first time with LS.

\section{RESULTS}

\section{Molecular data}

A PTPN11 heterozygous sequence variation of the coding sequence was detected in 13 of the 14 unrelated index cases tested, and five relatives. Four different nucleotide changes were found. A missense variation c.836A $\rightarrow$ G/p.Y279C in exon 7 was identified in seven subjects (six unrelated probands and one mother). A c.836A $\rightarrow$ C/p.Y279S was found in one sporadic proband. A missense variation c.1403C $\rightarrow$ T/p.T468M

Abbreviations: $A M L$, acute myeloid leukaemia; $C M P$, cardiomyopathy; LS, LEOPARD syndrome; MVP, mitral valve prolapse; NS, Noonan syndrome; PS, pulmonary stenosis 


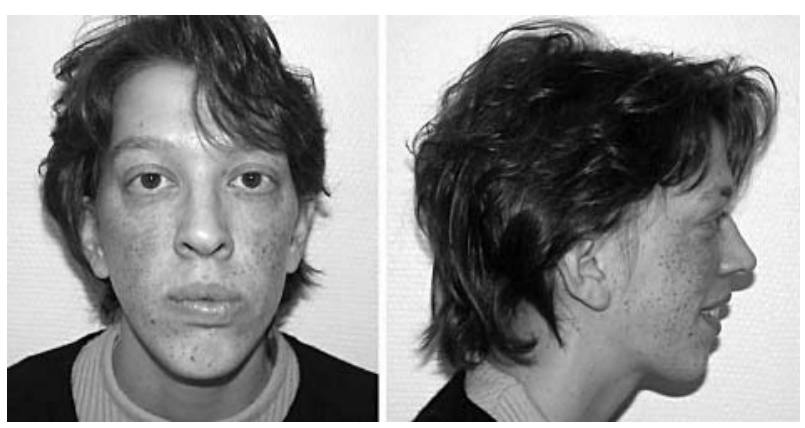

Figure 1 Face and profile of patient 3. Reproduced with permission.

in exon 12 was identified in eight subjects (five unrelated probands, one father, one mother, and one clinically affected sib). A missense variation c.1529A $\rightarrow$ C/p.Q510P in exon 13 was found in two probands and one affected mother. Parental genotyping was not possible for seven probands, none of whose parents were clinically suspect of LS. None of these sequence variations were found in a series of more than 320 patients who were referred to our institution for NS, nor in the unaffected parents of these children.

\section{Clinical data}

Pooled clinical data, sorted by mutation, are presented in table 1 for all probands and four out of five related carriers with classical mutations and sufficient clinical data. Many patients showed heart defects. Among the Y279C patients, one had PS and cardiomyopathy (CMP), another had mitral valve prolapse (MVP), and two had, respectively, septal and generalised myocardial hypertrophy without structural anomalies. In the T468M group, two patients had PS, MVP, and septal hypertrophy, one had aortic stenosis, and one pure MVP. The three patients with the Q510P mutation had classical, mild LS phenotypes, with normal growth and intelligence (patients 1 to 3 , table 1). One of those children had mild hearing impairment, whereas another was severely affected. Patient 3 (figs 1 and 2) had MVP. Her lentigines were profuse and associated with café au lait spots. Patient 4 developed acute myeloid leukaemia (AML) of the FAB-M2 subtype with normal cytogenetics. Two affected patients (one proband and his father), for whom no mutations were detected, had lentigines and multiple naevi associated with a marfanoid habitus (patients 5 and 6, table 1). Their facial appearance was thought to compatible with LS or NS. Interestingly, the father had aortic root dilatation but no eye anomalies, whereas the boy, despite pectus deformity and scoliosis, was $186 \mathrm{~cm}$ tall.

We compared the phenotypes for Y279C and T468M for patients of our series grouped with those previously reported in the literature using non-parametric test (table 1). No statistically significant differences were observed for most parameters except for the frequency of abnormal EKG. Other apparent differences between the two mutations (a trend for growth retardation and deafness in Y279C patients, and an

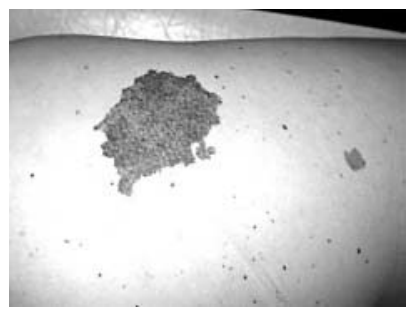

Figure 2 Close up view of skin lesions. Note co-existence of true lentigines and wider, dark pigmented spots (atypical café au lait spots). excess of heart defects other than PS in T468M patients) did not reach significance. Further study will be necessary to clarify if these trends are valid or just stochastic sampling effects (table 1).

\section{DISCUSSION}

NS causative defects are not randomly distributed in SHP-2. Most ( $>95 \%$ ) affect residues located in or close to the N-SH2 and protein tyrosine phosphatase interacting surfaces. To date, all molecular lesions have been heterozygous missense changes suspected of inducing a gain of function effect. In contrast to NS, LS is highly specific for PTPNIl and mutations have been identified in 15 out of the 17 patients reported in the literature..$^{3-7}$ Defects reported in LS are restricted in diversity since only two recurrent mutations, one in exon 7 (c.836A $\rightarrow$ G/p.Y279C) and one in exon 12 (c.1403C $\rightarrow$ T/p.T468M), have been reported (a clinical summary of those patients with sufficient clinical data are presented in table 1). A third mutation, c.1517A $\rightarrow$ C/p.Q506P, has been reported in a single patient. ${ }^{5}$ Only two typical LS patients reported so far have been negative for PTPNIl mutation screening. ${ }^{4}$ With only one of 14 LS cases not having a detectable mutation, our data confirm the high frequency of the PTPN11 mutation in LS.

If we combine our patients with those reported in the literature, ${ }^{2-6}$ taking into account the fact that patients briefly reported by Digilio $^{2}$ were later described in more detail by Sarkozy $^{4}$ (E Conti, personal communication), we reach a total of 28/31 (90\%) LS patients with PTPN11 mutations. Exon 7, 12 , and 13 mutations are, respectively, found in 53, 36, and $10 \%$ of the 28 cases with mutations. Although mutations responsible for NS affect either the N-SH2 or PTP domain, those responsible for LS seem to be restricted to the PTP domain. LS mutations are distinct from NS mutations. The specific association of LS mutations with skin pigmentation abnormalities is the most obvious difference, and is not limited to lentigines. Café au lait spots may herald lentigines, and are much more common in LS than in NS (15/24 subjects with LS in our review). As lentigines are often undetectable in infancy, distinction between NS and LS may be difficult in young children, and may explain why both Y279C and T468M substitutions were reported in patients without lentigines. The age of the patient with NS and $\mathrm{Y}^{279 \mathrm{C}^{1}}$ was not given. The two children with the T468M mutation, who were free of lentigines at the ages of 5 and 8.5, respectively, both showed café au lait spots, and the carrier mother displayed multiple lentigines. ${ }^{7}$ Zenker $e t$ al ${ }^{7}$ suggested other genotype/phenotype associations for the T468M mutation: less adverse effect on body growth, and lower prevalence of PS but more CMP. A low prevalence of mental handicap seems another characteristic. Our data combined with the literature confirm these trends, and indicate that the Y279C and T468M mutations may have slightly different expressions. Comparison of T468M and Y279C phenotypes showed a significant excess of EKG anomalies in Y279C, and trends toward more frequent deafness and growth retardation, and less frequent heart defects. A trend for café au lait spots cannot be distinguished, as patients harbouring each of these mutations are relatively different in age. The Y279C mutation appears to lead to a more characteristic LS phenotype, whereas T468M seems to result in a mixed NS-LS phenotype. However, these data need to be confirmed by further studies.

Two previously undescribed PTPN11 mutations were found in our series of patients with LS. These mutations are both located within the cluster of activating mutations in exons 7 and 13. The first affects Y279 and changes it into a serine instead of a cysteine. This mutation has been observed in a boy with typical LS syndrome who also had AML. NS is known to be associated with a higher risk of developing 
Table 1 Pooled clinical data sorted by mutation for 13 literature cases and 19 LS from this study

\begin{tabular}{|c|c|c|c|c|c|c|c|c|c|c|c|c|c|}
\hline \multirow[b]{2}{*}{ Mutation } & \multicolumn{3}{|l|}{ Y279C } & \multicolumn{3}{|l|}{ T468M } & \multirow{2}{*}{$\begin{array}{l}\text { Fisher } \\
\text { exact } \\
\text { test } \\
\text { (two } \\
\text { tailed)* }\end{array}$} & \multicolumn{3}{|l|}{ Q510P } & \multirow{2}{*}{$\begin{array}{l}\text { Y279S } \\
\text { Pt } 4\end{array}$} & \multicolumn{2}{|c|}{ No mutation } \\
\hline & $\begin{array}{l}\text { Liter- } \\
\text { ature } \\
(n=6)\end{array}$ & $\begin{array}{l}\text { This } \\
\text { series } \\
(n=6)\end{array}$ & $\begin{array}{l}\text { Com- } \\
\text { bined }\end{array}$ & $\begin{array}{l}\text { Liter- } \\
\text { ature } \\
(n=7)\end{array}$ & $\begin{array}{l}\text { This } \\
\text { series } \\
n=8)\end{array}$ & $\begin{array}{l}\text { Com- } \\
\text { bined }\end{array}$ & & $\begin{array}{l}\text { Pt } 1 \\
\text { (mother) }\end{array}$ & $\begin{array}{l}\text { Pt } 2 \\
\text { (prob- } \\
\text { and) }\end{array}$ & Pt 3 & & $\begin{array}{l}\text { Pt } 5 \\
\text { (prob- } \\
\text { and) }\end{array}$ & $\begin{array}{l}\text { Pt } 6 \\
\text { (father) }\end{array}$ \\
\hline Mean age at report & $\begin{array}{l}12 \text { years } \\
3 \text { months }\end{array}$ & 13 years & & $\begin{array}{l}11 \text { years } \\
11 \text { months }\end{array}$ & 19 years & & & $?$ & 12 years & 25 years & 6 years & 14 years & 41 years \\
\hline Mean BW (g) & $?$ & 3530 & & $?$ & 4042 & & & $?$ & 3740 & 4700 & 3570 & 4220 & 3160 \\
\hline Mean $B L(\mathrm{~cm})$ & $?$ & 50.6 & & $?$ & 50.4 & & & $?$ & 51 & 53 & 51 & 49.5 & $?$ \\
\hline Mean birth OFC $(\mathrm{cm})$ & $?$ & 35.1 & & $?$ & 35.75 & & & $?$ & 37 & 36 & 34.5 & 36 & $?$ \\
\hline Lentigines $\dagger$ & $6 / 6$ & $6 / 6$ & $12 / 12$ & $5 / 7$ & $7 / 7$ & $12 / 14$ & 1 & $Y$ & $Y$ & $Y$ & $Y$ & $Y$ & $Y$ \\
\hline Café au lait spots & $2 / 4$ & $3 / 6$ & $5 / 10$ & $7 / 7$ & $3 / 7$ & $10 / 14$ & 0.4 & $\mathrm{~N}$ & $Y$ & $Y$ & $\mathrm{~N}$ & $\mathrm{~N}$ & $\mathrm{~N}$ \\
\hline Pulmonary stenosis $†$ & $1 / 6$ & $1 / 6$ & $2 / 12$ & $1 / 7$ & $2 / 7$ & $3 / 14$ & 0.66 & & $\mathrm{~N}$ & $Y$ & $\mathrm{~N}$ & $\mathrm{~N}$ & $\mathrm{~N}$ \\
\hline Heart defect (not PS) & $1 / 5$ & $2 / 6$ & $3 / 11$ & $4 / 7$ & $4 / 7$ & $8 / 14$ & 0.22 & $N$ & $Y$ & $Y$ & $\mathrm{~N}$ & $\mathrm{~N}$ & $Y$ \\
\hline Cardiomyopathy & $3 / 6$ & $3 / 6$ & $6 / 12$ & $2 / 7$ & $4 / 7$ & $6 / 14$ & 1 & $N$ & $\mathrm{~N}$ & $\mathrm{~N}$ & $Y$ & $\mathrm{~N}$ & $\mathrm{~N}$ \\
\hline $\begin{array}{l}\text { EKG conduction } \\
\text { anomalies } †\end{array}$ & $2 / 2$ & $3 / 5$ & $5 / 7$ & $1 / 7$ & $1 / 6$ & $2 / 13$ & $0.02^{*}$ & $?$ & Y & $\mathrm{N}$ & $?$ & $\mathrm{~N}$ & $Y$ \\
\hline Retardation of growtht & $2 / 6$ & $2 / 5$ & $4 / 11$ & $1 / 7$ & $0 / 6$ & $1 / 13$ & 0.13 & $N$ & $\mathrm{~N}$ & $\mathrm{~N}$ & $\mathrm{~N}$ & $\mathrm{~N}$ & $\mathrm{~N}$ \\
\hline Deafness $\dagger$ & $0 / 3$ & $2 / 6$ & $2 / 9$ & $0 / 7$ & $0 / 7$ & $0 / 14$ & 0.14 & $\mathrm{~N}$ & $Y$ & $Y$ & $Y$ & $\mathrm{~N}$ & $\mathrm{~N}$ \\
\hline Abnormal genitalia† & $1 / 1$ & $0 / 6$ & $1 / 7$ & $?$ & $1 / 7$ & $1 / 7$ & 1 & $\mathrm{~N}$ & $\mathrm{~N}$ & $\mathrm{~N}$ & $\mathrm{~N}$ & $\mathrm{~N}$ & $\mathrm{~N}$ \\
\hline Cryptorchidism & $1 / 2 M$ & $1 / 3 M$ & $2 / 5 \mathrm{M}$ & $0 / 2 M$ & $1 / 5 \mathrm{M}$ & $1 / 7 \mathrm{M}$ & & & $Y$ & & $\mathrm{~N}$ & $\mathrm{~N}$ & \\
\hline Mental retardation & $1 / 6$ & $2 / 6$ & $3 / 12$ & $2 / 7$ & $1 / 7$ & $3 / 14$ & 1 & $N$ & $\mathrm{~N}$ & $\mathrm{~N}$ & $\mathrm{~N}$ & $\mathrm{~N}$ & $\mathrm{~N}$ \\
\hline OFC $\rightarrow$ p75 & $3 / 6$ & $0 / 3$ & $3 / 9$ & $4 / 7$ & $1 / 5$ & $5 / 12$ & 1 & & & & & $\mathrm{~N}$ & $\mathrm{~N}$ \\
\hline Triangular face & $1 / 2$ & $3 / 6$ & $4 / 8$ & - & $4 / 7$ & $4 / 7$ & 1 & $N$ & Y & $Y$ & $\mathrm{~N}$ & $\mathrm{~N}$ & $\mathrm{~N}$ \\
\hline Ocular hypertelorism $†$ & $5 / 6$ & $3 / 6$ & $8 / 12$ & $7 / 7$ & $3 / 7$ & $10 / 14$ & 1 & $N$ & $\mathrm{~N}$ & $\mathrm{~N}$ & Y & $\mathrm{N}$ & Y \\
\hline Ptosis & $6 / 6$ & $3 / 6$ & $9 / 12$ & $5 / 7$ & $3 / 7$ & $8 / 14$ & 0.43 & $N$ & $\mathrm{~N}$ & $\mathrm{~N}$ & $\mathrm{~N}$ & $\mathrm{~N}$ & $\mathrm{~N}$ \\
\hline Prognathism & $?$ & $2 / 6$ & $2 / 6$ & - & $2 / 7$ & $2 / 7$ & 1 & $\mathrm{~N}$ & $\mathrm{~N}$ & $Y$ & $\mathrm{~N}$ & $\mathrm{~N}$ & $\mathrm{~N}$ \\
\hline Pterygium colli & $0 / 2$ & $1 / 6$ & $1 / 8$ & - & $2 / 7$ & $2 / 7$ & 0.57 & $\mathrm{~N}$ & $\mathrm{~N}$ & $\mathrm{~N}$ & $Y$ & $\mathrm{~N}$ & $\mathrm{~N}$ \\
\hline $\begin{array}{l}\text { Pectus excavatum/ } \\
\text { carinatum }\end{array}$ & $2 / 5$ & $6 / 7$ & $8 / 12$ & $5 / 7$ & $5 / 7$ & $10 / 14$ & 1 & $N$ & $\mathrm{~N}$ & $\mathrm{~N}$ & $\mathrm{~N}$ & $Y$ & $\mathrm{~N}$ \\
\hline Scoliosis & $1 / 2$ & $2 / 7$ & $3 / 9$ & - & $1 / 7$ & $1 / 7$ & 0.58 & $N$ & $\mathrm{~N}$ & $\mathrm{~N}$ & $\mathrm{~N}$ & Y & $\mathrm{N}$ \\
\hline Coagulation abnormalities & $1 / 1$ & $1 / 4$ & $2 / 5$ & - & $2 / 3$ & $2 / 3$ & & $N$ & $Y$ & $Y$ & $\mathrm{~N}$ & $\mathrm{~N}$ & $\mathrm{~N}$ \\
\hline
\end{tabular}

${ }^{*}$ Comparison of $\mathrm{Y} 279 \mathrm{C}$ with T468M; toriginal LEOPARD acronymic keywords.

$B L$, birth length; BW, birth weight; $M$, male; N, no; OFC, occipitofrontal circumference; $Y$, yes.

juvenile myelomonocytic leukaemia (JMML) and possibly AML. Moreover, somatic PTPN1I mutations have been reported in sporadic JMML, AML, and acute lymphoblastic leukaemia, strengthening the link between SHP-2 and leukaemogenesis. ${ }^{8}$ AML with somatic PTPNIl mutations preferentially exhibits a monocytic subtype (FAB-M5), which is not the case in our patient. Whether or not LS or mutations associated with LS increase the risk for AML remains to be clarified

Our study confirms the high frequency of PTPNIl mutations in LS and the specificity of the mutations, which are the only mutations for which a high genotype/phenotype correlation is described. Whether the non-mutated family represents atypical LS or a distinct entity remains open to discussion. The pathogenic mechanisms that cause these mutations to specifically exhibit a dermatological phenotype (and conduction anomalies) is at present unclear.

\section{Authors' affiliations}

B Keren, A Hadchouel, S Saba, Y Sznajer, C Baumann, A Verloes,

H Cavé, Genetic Department, Hôpital Robert Debré (AP-HP), Paris, France

D Bonneau, Genetic Department, Angers University Hospital, Angers, France

B Leheup, Genetic Department, Nancy University Hospital, Nancy,

France

O Boute, Genetic Department, Lille University Hospital, Lille, France

D Gaillard, Histo-Embryo-Cytogenetic Department, Reims University Hospital, Reims, France

D Lacombe, Genetic Department, Bordeaux University Hospital, Bordeaux, France

V Layet, Genetic Unit, Le Havre Hospital, Le Havre, France

S Marlin, Genetic Department, Hôpital Armand Trousseau (AP-HP), Paris, France

G Mortier, Genetic Department, Ghent University Hospital, Ghent, Belgium
A Toutain, Genetic Department, Tours University Hospital, Tours, France C Beylot, Department of Dermatology, Haut-Léveque University Hospital, Bordeaux, France

This work has been supported in part by grants from the Programme Hospitalier de Recherche Clinique (PHRC) National (AOM02004).

Conflict of interest: none declared.

Correspondence to: Hélène Cavé, Laboratoire de Biochimie Génétique, Hôpital Robert Debré, 48, Boulevard Sérurier, 75019 Paris, France; cave@infobiogen.fr

Received 8 June 2004

Accepted for publication 10 June 2004

\section{REFERENCES}

1 Tartaglia M, Mehler EL, Goldberg R, Zampino G, Brunner HG, Kremer H, van der Burgt I, Crosby AH, lon A, Jeffery S, Kalidas K, Patton MA, Kucherlapati RS, Gelb BD. Mutations in PTPN1 1, encoding the protein tyrosine phosphatase SHP-2, cause Noonan syndrome. Nat Genet 2001;29:465-8.

2 Digilio MC, Conti E, Sarkozy A, Mingarelli R, Dottorini T, Marino B, Pizzuti A, Dallapiccola B. Grouping of multiple-lentigines/LEOPARD and Noonan syndromes on the PTPN11 gene. Am J Hum Genet 2002;71:389-94.

3 Legius E, Schrander-Stumpel C, Schollen E, Pulles-Heintzberger C, Gewillig M, Fryns JP. PTPN1 1 mutations in LEOPARD syndrome. J Med Genet 2002;39:571-4.

4 Sarkozy A, Conti E, Seripa D, Digilio MC, Grifone N, Tandoi C, Fazio VM, Di CV, Marino B, Pizzuti A, Dallapiccola B. Correlation between PTPN1 1 gene mutations and congenital heart defects in Noonan and LEOPARD syndromes. J Med Genet 2003;40:704-8.

5 Conti E, Dottorini T, Sarkozy A, Tiller GE, Esposito G, Pizzuti A, Dallapiccola B. A novel PTPN11 mutation in LEOPARD syndrome. Hum Mutat 2003;21:654.

6 Digilio MC, Pacileo G, Sarkozy A, Limongelli G, Conti E, Cerrato F, Marino B, Pizzuti A, Calabro R, Dallapiccola B. Familial aggregation of genetically heterogeneous hypertrophic cardiomyopathy: a boy with LEOPARD syndrome due to PTPN 11 mutation and his nonsyndromic father lacking PTPN1 1 mutations. Birth Defects Res Part A Clin Mol Teratol 2004;70:95-8.

7 Zenker M, Buheitel G, Rauch R, Koenig R, Bosse K, Kress W, Tietze HU Doerr HG, Hofbeck M, Singer H, Reis A, Rauch A. Genotype-phenotype correlations in Noonan syndrome. J Pediatr 2004;144:368-74.

8 Tartaglia M, Niemeyer CM, Shannon KM, Loh ML. SHP-2 and myeloid malignancies. Curr Opin Hematol 2004;1 1:44-50. 